Revista Brasil. Bot., V.32, n.1, p.131-142, jan.-mar. 2009

\title{
Desenvolvimento reprodutivo de Hyptis suaveolens (L.) Poit.: relação entre fotoperíodo, densidade celular meristemática e padrão de expressão de um ortólogo putativo do gene LEAFY de arabidopsis
}

\author{
FELIPE TERRA MARTINS ${ }^{1,2}$ e MARCELO POLO ${ }^{1}$
}

(recebido: 23 de novembro de 2006; aceito: 18 de dezembro de 2008)

\begin{abstract}
Reproductive development of Hyptis suaveolens (L.) Poit.: relationship among photoperiod, meristem cell density and expression pattern of a putative arabidopsis gene LEAFY ortholog). Hyptis suaveolens (L.) Poit. (Lamiaceae) is a typical invasive plant that produces an essential oil with several biological properties. The largest essential oil content is found at the flowers. So, advances in the current knowledge about the H. suaveolens reproductive development are important when the essential oil productivity is sought. Furthermore, the comprehension of the mechanisms involved in the H. suaveolens floral induction would be useful to clarify the adaptive responses in invasive plants. We here reported some H. suaveolens reproductive development features. The plants were grown at two photoperiodic treatments (natural photoperiod from Alfenas, Minas Gerais, Brazil and natural photoperiod extended of $16 \mathrm{~h}$ ). Samples of floral and vegetative aerial apices were taken at five different periods of time, for anatomical and scanning electron microscopic analysis, as well as in situ hybridization experiments, in order to detect the transcripts of a putative ortholog of Arabidopsis thaliana LEAFY gene. Hyptis suaveolens is a short day plant, with critical photoperiod nearby $13 \mathrm{~h}$. The cell density has increased according to higher vegetative or floral meristem activities. The putative ortholog of LEAFY in $H$. suaveolens has shown an expression pattern similar to that reported in Antirrhinum and Arabidopsis, although it was also expressed in vegetative apices at the natural photoperiod plants. Nevertheless, under extended natural photoperiod $(16 \mathrm{~h})$ no gene expression was detected in vegetative meristem. These results suggest a basal expression of LEAFY in H. suaveolens vegetative meristem, which is strongly decreased by extended day length conditions, or is increased under photoperiods lower than $13 \mathrm{~h}$, when suitable levels are reached for floral determination.
\end{abstract}

Key words - expression pattern, gene LEAFY, Hyptis suaveolens, invasive plant, Lamiaceae

RESUMO - (Desenvolvimento reprodutivo de Hyptis suaveolens (L.) Poit.: relação entre fotoperíodo, densidade celular meristemática e padrão de expressão de um ortólogo putativo do gene LEAFY de arabidopsis). Hyptis suaveolens (L.) Poit. é uma planta da família Lamiaceae, considerada uma espécie tipicamente invasora. Entretanto, é produtora de óleo essencial, ao qual várias atividades biológicas são atribuídas. Informações sobre o desenvolvimento reprodutivo nesta espécie seriam úteis à elucidação de mecanismos adaptativos relacionados à indução floral em espécies invasoras, e ao incremento na produção de óleo essencial, devido sua preponderância nas flores. Assim, aqui caracterizamos alguns aspectos do desenvolvimento reprodutivo em Hyptis suaveolens. Plantas de $\mathrm{H}$. suaveolens foram submetidas a dois tratamentos fotoperiódicos (fotoperíodo natural de Alfenas e fotoperíodo mínimo de 16 h) para amostragem de ápices aéreos vegetativos e florais em cinco datas. Nestes materiais botânicos foram realizadas análises anatômicas, ensaios de hibridização in situ para detecção dos transcritos de um ortólogo putativo de LEAFY e microscopia eletrônica de varredura. Hyptis suaveolens é uma planta de dias curtos, com fotoperíodo crítico em torno de $13 \mathrm{~h}$. A atividade meristemática vegetativa ou floral pôde ser evidenciada pela densidade celular. O ortólogo putativo de LEAFY em H. suaveolens exibiu o padrão de expressão clássico descrito em Antirrhinum e Arabidopsis, mas também foi expresso em ápices vegetativos de plantas cultivadas sob fotoperíodo natural, independente da época de amostragem. Entretanto, não foi expresso em meristemas vegetativos de plantas cultivadas em fotoperíodo mínimo de $16 \mathrm{~h}$. Estes resultados sugerem uma expressão basal de LEAFY em meristemas vegetativos de $H$. suaveolens, que é fortemente reduzida sob fotoperíodo mínimo de $16 \mathrm{~h}$ ou incrementada em fotoperíodos inferiores a $13 \mathrm{~h}$, atingindo níveis satisfatórios à determinação floral.

Palavras-chave - espécie invasora, gene LEAFY, Hyptis suaveolens, Lamiaceae, padrão de expressão

\section{Introdução}

Hyptis suaveolens (L.) Poit. é uma erva ereta anual, com altura oscilando entre um a dois metros (Silva et al.

\footnotetext{
1. Universidade Federal de Alfenas, Departamento de Farmácia, Rua Gabriel Monteiro da Silva, 700, 37130-000 Alfenas, MG, Brasil.

2._Autor para correspondência: felipetmartins@yahoo.com.br
}

2003) na fenofase de frutificação. É conhecida no Brasil como bamburral (nordeste) e erva canudo (sudeste e sul), onde é considerada invasora de lavouras de milho (Polo \& Felippe 1983) e de pastagens (Silva et al. 2003). Esta planta é encontrada em locais onde os solos foram drasticamente alterados, e está amplamente distribuída nas regiões tropicais e subtropicais (Wulff 1973), sendo utilizada na medicina popular como carminativa e para 
o tratamento de distúrbios gastrintestinais (Menghini et al. 1996, Grassi et al. 2005).

Como outras espécies da família Lamiaceae, $H$. suaveolens é uma planta semilenhosa, com poucos ramos laterais, caule quadrangular e filotaxia oposta (Zaidan et al. 1991). A epiderme de todos os órgãos aéreos apresenta alta densidade de tricomas glandulares (Silva et al. 2003). Tais anexos epidérmicos armazenam uma mistura de, principalmente, terpenóides no interior de uma cápsula situada no ápice da estrutura. Esta mistura perfaz o óleo essencial, cuja constituição vem sendo extensivamente investigada (Martins et al. 2006). Este óleo essencial tem sido avaliado quanto a sua ação antisséptica (Rojas et al. 1992), anticarcinogênica (Kingston et al. 1979); antibacteriana (Rojas et al. 1992, Asekun et al. 1999), antifúngica (Qureshi et al. 1997, Malele et al. 2003), larvicida contra Aedes aegypti (Noegroho \& Srimulyani 1997), anticonvulsivante (Akah \& Nwanbie 1993) e nematicida (Babu \& Sukul 1990).

Devido à notável importância econômica e o potencial farmacológico dos óleos essenciais de espécies do gênero Hyptis (Falcão \& Menezes 2003), são necessários estudos objetivando melhoramento, otimização e padronização da produção destas espécies. Tratando-se de $H$. suaveolens, esta necessidade é acentuada em função da ampla variação química e quantitativa do óleo essencial, que está sujeito principalmente às influências ambientais e genéticas (Martins et al. 2006, Grassi et al. 2005, Oliveira et al. 2005). Até mesmo os óleos essenciais isolados de diferentes partes de um mesmo quimiotipo de $H$. suaveolens apresentam variação na composição e no teor alcançado (Silva et al. 2003).

Acerca do teor, o óleo essencial extraído de plantas provenientes de Viçosa, Brasil, apresentou o maior percentual nas flores $(0,068 \%)$, seguido das folhas $(0,030 \%)$. Embora exista a oportunidade de trabalhos adicionais, que correlacionem a produção de óleo essencial nos diferentes órgãos de $H$. suaveolens com variáveis afins, aparentemente as flores consistem no principal órgão de armazenamento de óleo essencial no vegetal. Desta forma, o cultivo de $H$. suaveolens visando a produção quantitativa de óleo essencial para fins medicinais requer futuramente a otimização do florescimento.

A regulação do florescimento em muitas espécies é afetada por fatores ambientais, em particular pela temperatura e fotoperíodo. Em Hyptis brevipes foi relatado um forte controle das condições fotoperiódicas sobre a regulação do florescimento, inclusive sendo demonstrado o potencial desta espécie para estudos de inibição floral (Zaidan et al. 1991). Dados obtidos em Antirrhinum majus (Coen et al. 1990) e Arabidopsis thaliana (Weigel et al. 1992) permitiram a detecção de alguns dos genes envolvidos na regulação da indução e diferenciação floral. Dentre estes, um gene promotor aparentemente desempenha um papel chave na determinação de identidade do meristema floral, denominado FLORICAULA (FLO) em Antirrhinum (Coen et al. 1990) e seu homólogo LEAFY (LFY) em Arabidopsis (Weigel et al. 1992). A expressão constitutiva de homólogos de LFY isolados em diversas espécies de plantas é capaz de promover a indução do florescimento em Arabidopsis, possuindo este gene semelhanças estruturais e expressivas entre espécies de vários táxons vegetais (Dornelas \& Rodriguez 2005, Dornelas et al. 2004, Frohlich \& Parker 2000, Southerton et al. 1998). Homólogos de FLO/LFY são altamente conservados entre espécies filogeneticamente distantes (Frohlich \& Parker 2000), ocorrendo maior similaridade entre as sequiências de aminoácidos da região C-terminal das proteínas codificadas por estes genes, como por exemplo, há identidade de $84 \%$ entre as regiões C-terminal dos fatores de transcrição protéicos codificados por FLO (Antirrhinum majus) e por EgLFY (ortólogo de LFY em Eucalyptus grandis) (Dornelas et al. 2004). Já a região $\mathrm{N}$-terminal é menos conservada entre as proteínas codificadas pelos ortólogos de FLO/LFY isolados de diversas espécies. Novamente podemos citar a comparação entre FLO e EgLFY, onde existe identidade de 58\% entre as seqüências de aminoácidos na região $\mathrm{N}$-terminal (Dornelas et al. 2004). Embora estas observações reflitam uma possível conservação funcional entre os homólogos de FLO/LFY em espécies pouco relacionadas filogeneticamente, variações significativas a respeito dos padrões de expressão destes genes vêm sendo relatadas (Dornelas et al. 2004, Veit et al. 2004). Em Antirrhinum, FLO é expresso exclusivamente durante a fase reprodutiva nas brácteas e meristemas florais (Coen et al. 1990), enquanto que ortólogos deste gene são também expressos em baixas intensidades nos primórdios foliares de outras espécies, como em Arabidopsis (Blázquez et al. 1997), tabaco (Kelly et al. 1995), ervilha (Hofer et al. 1997), petúnia (Souer et al. 1998) e tomate (Rosales et al. 1999). Contrapondo o padrão de expressão aproximado dos ortólogos de FLO/LFY em dicotiledôneas, as espécies de monocotiledôneas reforçam a hipótese de divergência funcional deste gene. Tal evidência é notada, por exemplo, pela ausência de relação entre a iniciação de meristemas florais e a expressão de RLF, o ortólogo de FLO/LFY no arroz (Kyozuka et al. 1998), e pela expressão de LtLFY, o ortólogo de FLO/LFY no joio, ocorrer somente após outros genes que são ativados por LFY em dicotiledôneas terem sido expressos nesta gramínea (Gocal et al. 2001). Para tentar compreender a evolução de FLO/LFY nos 
táxons vegetais, alguns estudos foram conduzidos em angiospermas basais (peperômias) e em espécies de gimnospermas (Frohlich \& Meyerowitz 1997, Frohlich \& Parker 2000), contudo apenas dados estruturais relacionados às sequiências de ortólogos de FLO/LFY foram obtidos, e pouco se sabe sobre a relação fisiológica destes genes nestas plantas. Alternativamente, uma provável função durante o desenvolvimento foliar foi atribuída aos ortólogos de FLO/LFY, baseada nas alterações foliares manifestadas em mutantes de ervilha (Hofer et al. 1997) e tomate (Rosales et al. 1999) com perda de função de UNIFOLIATA e FALSIFLORA, respectivamente.

No entanto, nenhum dado até o presente momento foi apresentado sobre características estruturais e funcionais de homólogos de FLO/LFY em espécies da família Lamiaceae, e poucos estudos semelhantes vêm sendo realizados com espécies invasoras, como e.g. na gramínea Lolium temulentum (Gocal et al. 2001).

Em Hyptis suaveolens o conhecimento dos processos que induzem e regulam o desenvolvimento reprodutivo não seria importante apenas para a conservação e melhoramento desta espécie, mas também viabilizaria o incremento na produção de óleo essencial, devido sua preponderância nas flores. Além destas contribuições, a compreensão de tais eventos auxiliaria na elucidação de mecanismos adaptativos relacionados à indução floral em espécies invasoras, nas quais o desenvolvimento reprodutivo está programado para promover uma propagação rápida e eficiente da espécie, respondendo na mesma velocidade em que as flutuações nos parâmetros ambientais ocorrem (Muller-Scharer et al. 2004). Como parte de nossos estudos sobre a otimização da produção de H. suaveolens visando à obtenção de óleo essencial qualificado farmacologicamente e, principalmente, em teores apreciáveis, este trabalho foi realizado para caracterizar aspectos do desenvolvimento reprodutivo em H. suaveolens, tais como interferências do fotoperíodo sobre a indução e diferenciação floral e suas correlações com o padrão de expressão de um ortólogo putativo de LFY, e a descrição concisa dos estágios da ontogênese reprodutiva.

\section{Material e métodos}

Localização - A cidade de Alfenas está localizada nas coordenadas de $21^{\circ} 27^{\prime} \mathrm{S}$ e $45^{\circ} 56^{\prime} \mathrm{W}$, a uma altitude de $880 \mathrm{~m}$, com clima tropical moderado úmido, sendo que as temperaturas do mês mais frio oscilam entre 13 e $16{ }^{\circ} \mathrm{C}$ e as do mês mais quente entre 21 e $23{ }^{\circ} \mathrm{C}$. Os invernos têm de dois a quatro meses secos com déficit hídrico pequeno, entre 10 a $30 \mathrm{~mm}$.
Seu regime de precipitações fica entre 1.400 a $1.700 \mathrm{~mm}$, sendo o seu regime de distribuição periódica, predominando no período mais quente do ano. A umidade relativa do ar apresenta média anual em torno de $70 \%$ (Carvalho \& Martins 1994).

Obtenção das núculas para semeadura - Plantas de Hyptis suaveolens vêm sendo cultivadas no viveiro da Universidade Federal de Alfenas (Unifal-MG), sendo que as núculas de $H$. suaveolens utilizadas na semeadura das plantas experimentais foram colhidas em dois indivíduos na fase de dispersão das sementes. A coleta foi feita manualmente e as núculas foram escolhidas, descartando as imaturas, danificadas e chochas, e armazenadas em sacos de papel em condições ambientais até o momento da semeadura.

Local de cultivo e preparo do substrato: grupos experimentais - Plantas de H. suaveolens foram cultivadas em casa de vegetação na área do viveiro da Unifal-MG, entre os meses de agosto de 2003 e março de 2004. Foram preparados $0,18 \mathrm{~m}^{3}$ de substrato, composto de solo, areia e esterco curtido de galinha na proporção 3:2:1 em volume. A este substrato foram adicionados fertilizantes químicos nas quantidades de: $20 \mathrm{~g}$ de sulfato de amônio, $10 \mathrm{~g}$ de fosfato de cálcio e $20 \mathrm{~g}$ de cloreto de potássio (Alves et al. 2000).

Para cada tratamento foram utilizados seis vasos plásticos com capacidade de 14 litros, sendo cultivada apenas uma única planta por vaso. Foi respeitada uma distância de $50 \mathrm{~cm}$ entre os centros dos recipientes e, entre estes e os limites das estantes. As plantas cultivadas em fotoperíodo natural permaneceram sob condições de luz ambiente, em fotoperíodo natural de Alfenas compreendido entre os meses de agosto de 2003 a março de 2004. Já as plantas cultivadas em fotoperíodo natural estendido foram mantidas sob fotoperíodo longo, que correspondeu ao fotoperíodo natural acrescido de complemento de 4 horas de luz artificial fornecida por lâmpada incandescente de baixa intensidade (General Electric, $100 \mathrm{w}, 1,6 \mu \mathrm{mol} \mathrm{m}^{-2} \mathrm{~s}^{-1}$ ) (Zaidan et al. 1991).

Assim foram obtidos os dois tratamentos, referentes às duas condições de fotoperíodo, com seis plantas cada. Nos dias seguintes à preparação do substrato e até as plantas completarem 30 dias de emergência, os recipientes foram irrigados diariamente. Após este período, os recipientes foram irrigados em dias intercalados.

Coleta de tecidos vegetais para análises anatômicas e ensaios de hibridização in situ - As coletas foram realizadas em cinco datas diferentes. Em todas as coletas, as seis plantas de cada tratamento foram amostradas. Na primeira coleta as plantas tinham cerca de 30 dias de idade ( 03 de outubro 2003; fotoperíodo de 12h11); na segunda coleta cerca de 60 dias (04 de novembro de 2003; fotoperíodo de 12h49); na terceira coleta cerca de 100 dias de idade (16 de dezembro de 2003; fotoperíodo de 13h18); na quarta coleta 130 dias (14 de janeiro de 2004; fotoperíodo de 13h11) e por fim, na quinta coleta as plantas apresentavam cerca de 150 dias de idade (02 de fevereiro de 2004; fotoperíodo de 12h55). A 
data de início do cultivo experimental foi marcada pela presença de no mínimo uma plântula emersa em cada recipiente (04 de setembro de 2003).

Os tecidos vegetais foram coletados retirando-se as regiões dos nós situados próximos ao ápice de ramos jovens, coletando-se inclusive a região apical destes ramos. Em todas as plantas de cada grupo experimental foram amostrados tecidos de vários ramos, sendo que estes segmentos de caule de aproximadamente $2 \mathrm{~mm}$ foram fixados em solução FAA em etanol 70\% (Johansen 1940). Em seguida foi aplicado vácuo $(60 \mathrm{mmHg})$ por 20 minutos e os materiais permaneceram 72 horas submersos em solução fixadora, sendo posteriormente desidratados em série alcoólica etílica, diafanizados em xilol, inclusos com parafina, emblocados e secionados longitudinalmente em micrótomo de rotação. Foram obtidos vários cortes longitudinais de $8 \mu \mathrm{m}$ de espessura, sendo destinados às análises anatômicas e aos ensaios de hibridização in situ.

Análises anatômicas - Para estas observações os cortes foram assentados em lâminas, desparafinados e corados com safranina 1\% em etanol 50\% (Berlyn \& Miksche 1976). A confecção final das lâminas foi feita com a resina Entellan ${ }^{\circledR}$.

Também foi estimada a densidade celular por meio de morfometria de contagem de pontos nas camadas adjacentes à túnica meristemática, em cortes onde a emissão dos primórdios foliares ou de sépalas havia ocorrido recentemente. Para cada grupo experimental foram utilizados seis cortes, constituindo um corte de cada planta, escolhido aleatoriamente, uma parcela. Utilizou-se um microscópio fotônico (Olympus ${ }^{\circledR}$ CBA), acoplado a uma câmera de vídeo $\left(\right.$ SV Micro SoundVision $\left.{ }^{\circledR}\right)$, e um retículo sobreposto à imagem do campo microscópico, projetada em monitor de 15 polegadas. Para cada parcela analisaram-se 15 campos aleatórios, obtendo-se o valor médio dessas medidas. A área teste do retículo foi de $625 \mu^{2}$ (Melo et al. 2005).

Nas amostras apresentando gemas florais, a densidade celular foi obtida no meristema floral e no meristema vegetativo apical dos ramos amostrados, enquanto que na ausência de gemas florais a estimativa da densidade celular foi realizada apenas no meristema vegetativo apical dos ramos. Uma amostra do material vegetal foi identificada, herborizada e incorporada ao acervo do Herbário da Universidade Federal de Alfenas sob o número HEFOA 00189.

Hibridização in situ - As preparações dos tecidos após as secções em micrótomo, assim como as técnicas para marcação da sonda de RNA e as condições de hibridização, foram procedidas conforme descrito anteriormente por Dornelas et al. $(1999,2000)$.

Foi utilizada uma sonda de RNA antisenso heteróloga para identificação dos transcritos de um ortólogo putativo de $L F Y$ em $H$. suaveolens nos diferentes grupos experimentais, épocas de coleta e estágios do desenvolvimento floral. Também foi sintetizada uma sonda senso, a qual foi utilizada como controle dos ensaios de hibridização. Para a marcação de ambas as sondas, foi utilizado o conjunto de reagentes para marcação de sondas não radioativas com digoxigenina (DIG-UTP), segundo as instruções do fabricante (Boehringer Mannheim/Roche 2000). Como molde para a marcação in vitro foi utilizado o cDNA completo de LFY de Arabidopsis thaliana (código At5g61850 para acesso no GenBank), clonado no plasmídeo pDW124 (Weigel et al. 1992). Os transcritos de um ortólogo putativo de $L F Y$ em H. suaveolens, hibridizados com a sonda antisenso, foram detectados pela visualização de um precipitado vermelho escuro produzido pela conversão enzimática do substrato pela fosfatase alcalina, conjugada ao anticorpo anti-digoxigenina. As lavagens dos materiais foram conduzidas em baixa estringência (2xSSC a $35^{\circ} \mathrm{C}$ ), a fim de evitar a inespecificidade de sinais. Os cortes hibridizados foram analisados imediatamente e fotografados com auxílio de um microscópio Zeiss Axiovert 35 (Dornelas et al. 2004).

Microscopia eletrônica de varredura - Algumas gemas florais jovens foram coletadas de cada uma das seis plantas cultivadas sob fotoperíodo natural, quando as mesmas tinham 150 dias de idade (quinta coleta), e imediatamente fixadas seguindo os mesmos procedimentos adotados para os materiais destinados às análises anatômicas. Porém após a desidratação em série alcoólica etílica, os materiais foram conservados em etanol absoluto a $4{ }^{\circ} \mathrm{C}$ até o momento da secagem pelo método de ponto crítico em $\mathrm{CO}_{2}$. Essa secagem foi feita em aparelho de ponto crítico Balzers, CPD-010, utilizando $\mathrm{CO}_{2}$ líquido. Em seguida os materiais foram montados em bases metálicas com fita adesiva de carbono condutivo, recobertos com ouro coloidal em aparelho de Ion Sputter Balzer, SCD-040, e observados a $15 \mathrm{kV}$ usando um microscópio eletrônico de varredura LEO $435 \mathrm{VP}$, na Universidade de São Paulo (ESALQ-NAP/MEPA) (Dornelas et al. 2004).

Análise estatística - Os resultados de densidade celular meristemática foram avaliados por análise de variância (ANOVA), sendo que as médias significativamente diferentes $(P<0,05)$ foram discriminadas pelo Teste de Tukey (Tukey 1991).

\section{Resultados e discussão}

Plantas mantidas sob fotoperíodo natural estendido não floresceram, ocorrendo apenas o desenvolvimento de ramos vegetativos axilares, enquanto plantas cultivadas em fotoperíodo natural floresceram 50 dias após a semeadura e permaneceram floridas durante todo o período de estudo. Hyptis suaveolens apresentou comportamento clássico de uma planta de dias curtos, uma vez que o fotoperíodo mínimo de 16 horas inibiu completamente a floração. Exemplares de $H$. suaveolens vêm sendo continuamente cultivados no viveiro da Universidade Federal de Alfenas, os quais apresentam desenvolvimento reprodutivo ativo sob condições 
fotoperiódicas naturais inferiores a 12 horas (fotoperíodo mínimo de 10h41), destacando-se inclusive florescimento precoce. Essa dependência fotoperiódica para o florescimento foi descrita previamente em outra espécie do gênero, Hyptis brevipes (Zaidan et al. 1991).

Algumas inflorescências axilares foram caracterizadas em amostras de plantas cultivadas em fotoperíodo natural e coletadas aos 30 e 60 dias de idade (fotoperíodos de $12 \mathrm{~h} 11$ e $12 \mathrm{~h} 49$, respectivamente), com predominância de flores isoladas nestas ocasiões. Contudo, aos 150 dias de idade (12h55) foram identificadas inflorescências axilares em todos os ápices aéreos analisados de plantas cultivadas sob fotoperíodo natural. Em plantas com 150 dias de idade, a indução e a diferenciação dos meristemas florais recém formados ocorreram simultaneamente ao processo de organogênese foliar. Esse desenvolvimento diferencial das inflorescências axilares pode estar relacionado a outros fatores ecofisiológicos, como, por exemplo, à temperatura, visto que o fotoperíodo foi aproximadamente similar nas três épocas de amostragem em questão. Zaidan et al. (1991) descreveram em Hyptis brevipes uma intensificação da floração mediante elevação da temperatura. Neste estudo não foi realizado o monitoramento diário desta variável ambiental, mas, durante o período referente às duas primeiras amostragens, as temperaturas médias mensais foram inferiores àquela relativa ao período da última coleta (plantas com 150 dias de idade). Provavelmente $H$. suaveolens se assemelhe à $H$. brevipes não apenas na dependência fotoperiódica mas, também, quanto à influência da temperatura para o florescimento. Generalizando, com relação à intensidade de florescimento, plantas cultivadas sob tais fotoperíodos inferiores a 13 horas são semelhantes aos exemplares que vêm sendo continuamente cultivados em Alfenas quando expostos aos fotoperíodos naturais inferiores a 12 horas, mas, existem diferenças de intensidade de florescimento dependentes da idade e da época de cultivo das plantas.

A diferenciação dos primórdios florais ocorreu de forma centrípeta e iniciou-se nas extremidades do meristema floral como cinco protrusões (figuras 1, 2), correspondentes às sépalas, seguido da diferenciação das pétalas que permaneceram recobrindo as estruturas internas (figura 3). Tricomas epidérmicos, inclusive tricomas glandulares reservatórios de óleos essenciais, foram originados em um estágio imediatamente posterior ao desenvolvimento primordial das sépalas (figura 1). As inflorescências axilares foram formadas pelos meristemas laterais (figura 4).

Secções anatômicas de plantas cultivadas sob fotoperíodo natural e coletadas aos 100 e 130 dias de idade (fotoperíodos de 13h18 e 13h11, respectivamente) revelaram a presença de meristemas florais latentes. Essa condição de latenciação dos meristemas florais axilares pode estar relacionada à elevação do fotoperíodo natural nestas datas de amostragem, similarmente ao relatado em $H$. brevipes, onde o fotoperíodo crítico está entre 12 e 13 horas. A latenciação do meristema foi observada também em níveis celulares, devido à redução do número de células no meristema floral de ramos coletados aos 100 dias de idade, quando o fotoperíodo natural atingiu o valor máximo entre as épocas de coletas (13h18). Nessa ocasião, a média obtida foi significativamente inferior não apenas em relação aos demais valores de densidade celular nos meristemas florais, mas também foi menor em comparação às médias obtidas em meristemas vegetativos de plantas coletadas aos 100 dias de idade e cultivadas em ambos os tratamentos (tabela 1). Por outro lado, as médias de densidade celular em meristemas florais intensamente ativos, coletados na primeira, segunda e quinta datas de amostragem, foram superiores àquelas obtidas em meristemas vegetativos coletados nas respectivas épocas de coleta, independentes dos tratamentos. Tal fato pode ser também verificado em meristemas florais latentes de ramos amostrados na quarta coleta (plantas de 130 dias de idade), evidenciando possíveis alterações mitóticas precoces induzidas pela redução fotoperiódica progressiva da terceira data de amostragem (fotoperíodo máximo de 13h18) para a quarta data de coleta (fotoperíodo de 13h11). Essas alterações celulares conduzirão os meristemas florais latentes para um estágio ativo na quinta coleta, fase esta caracterizada por forte elevação do número de células nos meristemas florais $(30,11 \pm 1,40$; média \pm desvio padrão). Nessa ocasião o desenvolvimento reprodutivo foi acelerado em relação às demais épocas de amostragem sob fotoperíodo natural. Comportamento similar é descrito em outras espécies durante a transição para a floração, como em Xanthium (Corbesier et al. 1996) e Citrus sinensis (Pereira et al. 2003), onde um significativo aumento no índice mitótico ocorre no ápice vegetativo após tratamento indutivo adequado. Contudo, em $H$. suaveolens meristemas florais aparentam manter índices mitóticos significativamente maiores quando comparados aos meristemas vegetativos, preferencialmente em condições fotoperiódicas naturais apropriadas à indução e diferenciação floral, ou seja, em fotoperíodos inferiores a 13 horas (primeira, segunda e quinta datas de amostragem). Na quarta data de amostragem, o índice mitótico dos meristemas florais também foi maior que a taxa de divisão celular dos meristemas vegetativos, todavia, o fotoperíodo foi superior a 13 horas (13h11). Mas, nessa ocasião, o fotoperíodo se encontrava em 

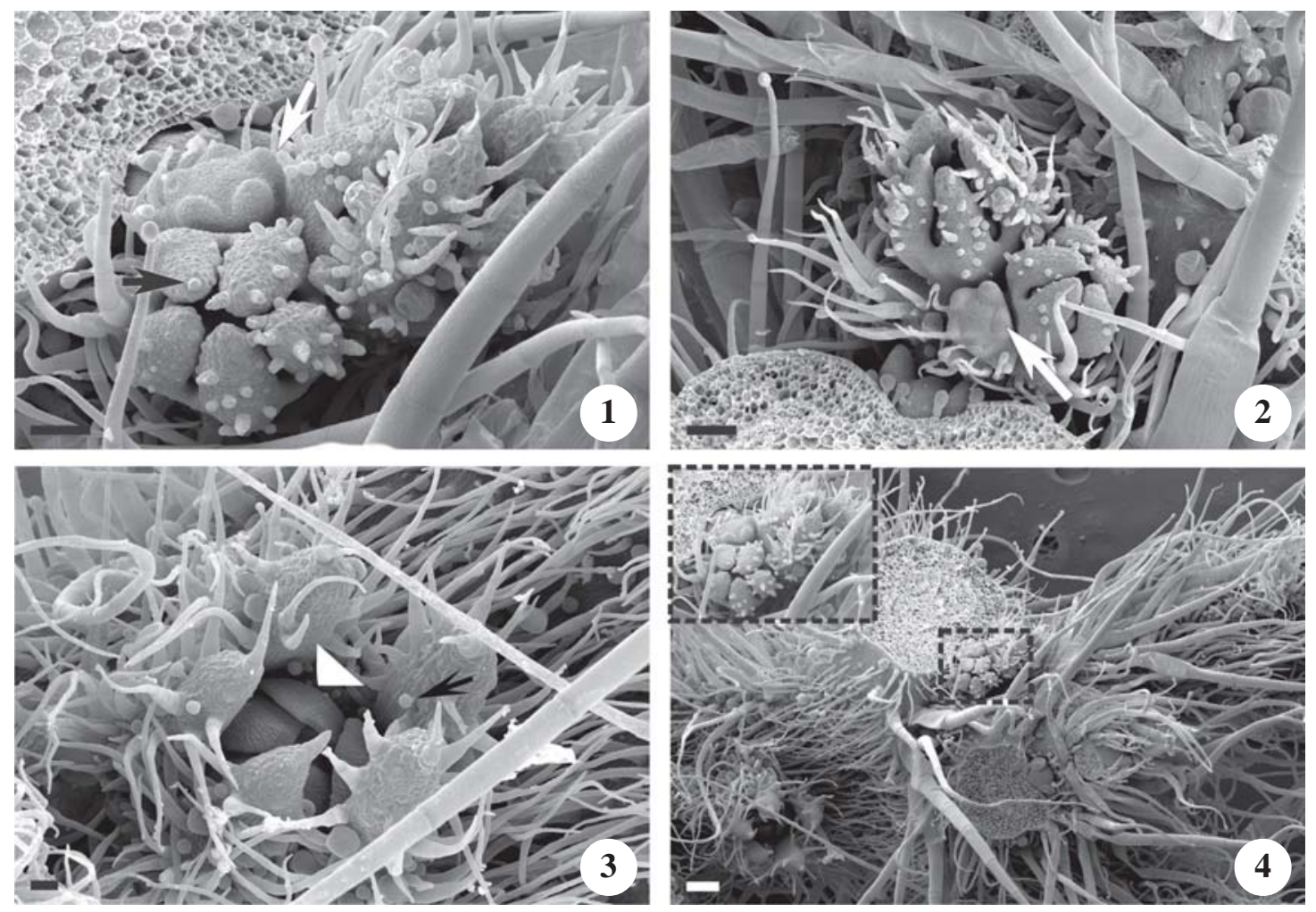

Figuras 1-4. Micrografias eletrônicas de varredura (MEV) de gemas florais de Hyptis suaveolens. 1, 2. Diferenciação inicial dos primórdios de sépalas nas extremidades dos meristemas florais como cinco protrusões (setas brancas). 3. Pétalas recémdiferenciadas recobrindo regiões meristemáticas internas (triângulo). 4. Inflorescência axilar em desenvolvimento (em destaque). Os materiais botânicos são de plantas de 150 dias de idade (quinta coleta) cultivadas sob fotoperíodo natural. Setas pretas $=$ tricomas glandulares. Barra $=20 \mu \mathrm{m}$ (figura 1); $30 \mu \mathrm{m}$ (figuras 2, 3); $100 \mu \mathrm{m}$ (figura 4).

Figures 1-4. Scan electron micrographs (SEM) of Hyptis suaveolens floral buds. 1, 2. Initial differentiation of sepal primordia in the floral meristem flanks as five protrusions (white arrows). 3. Newly differentiated petals recovering internal meristematic regions (triangle). 4. Development of axillary inflorescences (detached). The botanic materials are from 150 day-old plants (fifth sampling) cultivated under natural photoperiod. Black arrows $=$ glandular trichomes. Bar $=20 \mu \mathrm{m}$ (figure 1); $30 \mu \mathrm{m}$ (figures 2, 3); $100 \mu \mathrm{m}$ (figure 4).

diminuição após ter atingido o valor máximo na data de amostragem imediatamente anterior, indicando, portanto, um restabelecimento da atividade mitótica nos meristemas florais. Já o valor médio de densidade celular dos meristemas florais originados sob fotoperíodo natural de $13 \mathrm{~h} 18$ foi menor que aquele dos meristemas vegetativos coletados de plantas do tratamento correspondente, na mesma época de coleta. Isso prova que em $H$. suaveolens os índices mitóticos não estão condicionados ao tipo de meristema, floral ou vegetativo, e, sim, estão relacionados com a atividade meristemática e, conseqüentemente, com a organogêneses floral ou foliar/caulinar. Tal evidência é reforçada pela correlação existente entre os valores de densidade celular e o crescimento vegetativo de plantas cultivadas sob fotoperíodo natural acrescido de 4 horas de luz artificial. Nesse tratamento, a densidade celular alcançou um valor médio de 17,97 $\pm 1,00$ (média \pm desvio padrão) na terceira data de amostragem, quando as plantas se encontravam no auge do seu crescimento vegetativo, uma vez que o desenvolvimento reprodutivo foi inibido pela condição fotoperiódica. Por outro lado, na última data de amostragem, quando as plantas já haviam reduzido bruscamente o crescimento vegetativo, a densidade celular revelou um valor médio de 6,40 $\pm 0,52$ (média \pm desvio padrão), o menor valor de densidade celular observado. Sumarizando, os valores de densidade celular dependem fortemente da atividade mitótica do meristema. Então, para o estabelecimento de correlações entre tal parâmetro histológico e o tipo de meristema aéreo (floral ou vegetativo) é necessário levar em consideração a atividade meristemática. Adicionalmente, a atividade do meristema floral, por sua vez, é modulada pelas pequenas variações do fotoperíodo natural entre 12 e $13 \mathrm{~h}$. 
Tabela 1. Densidade celular nas camadas adjacentes à túnica meristemática de ápices jovens de plantas de Hyptis suaveolens cultivadas em diferentes tratamentos fotoperiódicos. Os dados apresentados consistem nas médias do número de células presentes em uma área de seção longitudinal de $625 \mu \mathrm{m}^{2}$, seguidos de seus respectivos valores de desvio padrão. (* Médias iguais entre os tratamentos fotoperiódicos em uma determinada idade $(P>0,05) ;{ }^{a}$ médias iguais entre as diferentes idades das plantas em um determinado tratamento $(P>0,05))$.

Table 1. Cell density at the innermost layers adjoining to tunica from early apical meristems of Hyptis suaveolens plants cultivated under different photoperiodic conditions. The displayed data are the means \pm standard deviation of cell number counted in a longitudinal section area of $625 \mu \mathrm{m}^{2}$. (* Equal means among the different photoperiodic conditions under unchangeable plant age condition $(P>0.05) ;{ }^{\text {a }}$ Equal means among the different plant ages under unchangeable photoperiodic condition $(P>0.05))$.

\begin{tabular}{llrrrrr}
\hline \multirow{2}{*}{$\begin{array}{l}\text { Tratamento } \\
\text { fotoperiódico }\end{array}$} & Meristema & \multicolumn{5}{c}{ Idade das plantas em dias } \\
\cline { 3 - 7 } & & \multicolumn{1}{c}{30} & 60 & 100 & \multicolumn{1}{c}{130} & 150 \\
\hline Natural (12-13 h) & Floral & $25,70 \pm 1,61$ & $20,43^{\mathrm{a}} \pm 0,50$ & $9,78 \pm 0,71$ & $19,96^{\mathrm{a}} \pm 0,82$ & $30,11 \pm 1,40$ \\
Natural (12-13 h) & Vegetativo & $* 11,76^{\mathrm{a}} \pm 0,46$ & $* 11,37^{\mathrm{a}} \pm 0,49$ & $12,40^{\mathrm{a}} \pm 0,35$ & $* 12,81^{\mathrm{a}} \pm 0,74$ & $12,76^{\mathrm{a}} \pm 0,62$ \\
Estendido (16 h) & Vegetativo & $* 13,11^{\mathrm{a}} \pm 0,80$ & $* 10,52 \pm 0,44$ & $17,97 \pm 1,00$ & $* 13,30^{\mathrm{a}} \pm 1,52$ & $6,40 \pm 0,52$ \\
\hline
\end{tabular}

O padrão de expressão do ortólogo putativo do gene LFY em $H$. suaveolens foi observado em meristemas reprodutivos de plantas cultivadas sob fotoperíodo natural de Alfenas, independente da época de amostragem e atividade meristemática. Inicialmente, a detecção foi uniforme em todo meristema (figuras 5, 6; materiais amostrados na primeira coleta), seguido de declínio nos órgãos recém diferenciados e manutenção do sinal de hibridização em áreas de desenvolvimento de primórdios florais (figuras 7-9; materiais amostrados nas segunda e quinta coletas), remanescendo a expressão nas anteras durante a formação do pólen (figura 10; material amostrado na quinta coleta). Após o término do desenvolvimento das estruturas florais o sinal de hibridização não foi mais detectado. Tal padrão de expressão é similar a outros padrões descritos para homólogos de LFY/FLO em espécies de vários táxons vegetais (Coen et al. 1990, Weigel et al. 1992, Southerton et al. 1998, Dornelas et al. 2004). Em seções anatômicas de ápices aéreos de plantas mantidas em fotoperíodo natural e coletados em todas as cinco datas de amostragem, o transcrito do ortólogo putativo de LEAFY também foi detectado em primórdios foliares, principalmente nos ápices, e nos respectivos meristemas vegetativos de origem, porém a baixas intensidades. As figuras 5 e 11 exibem fotomicrografias de materiais provenientes de plantas cultivadas sob fotoperíodo natural, os quais foram amostrados nas primeira e quarta coletas, respectivamente. Essas imagens são representativas dos demais materiais coletados nas outras datas, onde os sinais de hibridização são notados nos primórdios foliares e nos meristemas vegetativos. Embora a expressão de LEAFY, FLORICAULA e a maioria dos demais homólogos estar restrita a tecidos reprodutivos de Arabidopsis, Antirrhinum e outros gêneros, os resultados assemelham-se, em parte, ao estudo realizado em Eucalyptus grandis, onde foi verificado que EgLFY é expresso tanto em meristemas florais quanto em primórdios foliares de plantas adultas (Dornelas et al. 2004). Entretanto, este homólogo de LFY não é expresso no meristema vegetativo propriamente dito de $E$. grandis, diferentemente de $H$. suaveolens. Já em outra espécie tipicamente invasora, Lolium temulentum, LtLFY não é expresso em ápices vegetativos e somente é detectado tardiamente (cerca de 12 dias após indução floral de dias longos) nos meristemas e primórdios florais (Gocal et al. 2001), contrastando assim em vários aspectos com o padrão de expressão do ortólogo putativo de LFY em H. suaveolens. Contudo, comparações entre os padrões de expressão de homólogos de LFY nestas duas espécies invasoras não são muito informativas, devido principalmente às diferenças nos ciclos fotoperiódicos indutivos e nas respectivas classes das espécies em questão, dicotiledôneas (H. suaveolens) e monocotiledôneas (Lolium temulentum). O papel de genes relacionados a LFY é menos compreendido em monocotiledôneas do que em dicotiledôneas, e aparentemente a hierarquia da regulação floral envolvendo genes de identidade do meristema descrita em dicotiledôneas pode não ser conservada em monocotiledôneas (Gocal et al. 2001). A divergência funcional dos ortólogos de FLO/LFY em monocotiledôneas pode ser notada também em outras espécies, como no trigo, onde o gene WFL está associado com o desenvolvimento das espiguetas ao invés da especificação de identidade do meristema floral devido 
à ausência de detecção dos transcritos nos meristemas axilares onde se originam as espiguetas (Shitsukawa et al. 2006), e no milho, onde os transcritos das duas cópias ortólogas de FLO/LFY, ZFL1 e ZFL2, foram detectados em ápices vegetativos de plantas apresentando 20 dias de idade, incluindo também expressão nos primórdios foliares (Bomblies et al. 2003). Em contraste aos resultados obtidos para o trigo, os transcritos de ZFL1 e ZFL2 foram detectados nos meristemas das inflorescências em regiões onde as espiguetas se iniciam, e continuam a serem fortemente expressos nas espiguetas em desenvolvimento, incluindo expressão nos primórdios de órgãos florais (Bomblies et al. 2003). Ainda assim, existe semelhança entre $H$. suaveolens e Lolium temulentum e está restrita à variação de densidade celular nos meristemas, incondicionada às flutuações na expressão dos homólogos de LFY (Gocal et al. 2001). Dentre todos os padrões de expressão analisados, o mais compatível com este estudo foi observado em Chenopodium rubrum (Veit et al. 2004). Nessa espécie a expressão do ortólogo de LEAFY (CrFL) é regulada pelo fotoperíodo, onde os níveis do transcrito aumentam mediante exposição ao estímulo floral de dias curtos. CrFL também é expresso em meristemas vegetativos, desempenhando importante papel fisiológico tanto nestes tecidos quanto em gemas florais (Veit et al. 2004). Não foi possível discriminar as intensidades da coloração vermelha escura em meristemas florais, inviabilizando assim a determinação de diferentes níveis de expressão do ortólogo putativo de LEAFY em gemas florais de $H$. suaveolens, entre as datas de amostragem. Contudo, a expressão deste gene em ambos os meristemas florais e vegetativos de $H$. suaveolens aparenta estar condicionada ao fotoperíodo natural, oscilante entre 12 e 13 horas durante o período de estudo em Alfenas, uma vez que sob fotoperíodos superiores a 16 horas o sinal de hibridização não foi detectado em primórdios foliares e meristemas vegetativos. Nas datas de amostragem de materiais de plantas cultivadas sob fotoperíodo estendido, também não foi possível detectar sinal de hibridização nas estruturas mencionadas acima. A fotomicrografia de um material amostrado na quinta coleta (figura 12) é representativa dos demais materiais coletados nas outras datas. Trabalhos na literatura relatam a regulação positiva e rápida da expressão de homólogos de LFY em diversas angiospermas mediante exposição a estímulos florais, entre estes fotoperíodos adequados (Coen et al. 1990, Weigel et al. 1992). Em certos casos, este aumento na expressão através da regulação positiva é precedido por um nível basal de transcritos de LFY, evidenciando ser a quantidade deste gene um fator determinante para o desenvolvimento reprodutivo (Dornelas \& Rodriguez 2005). Não distante, os resultados aqui apresentados podem indicar expressão basal do ortólogo putativo de LFY em $H$. suaveolens nos tecidos vegetativos, mesmo quando o estímulo floral não é adequado (fotoperíodo de 13h18). Mediante regulação positiva, através do cultivo sob fotoperíodos inferiores a 13 horas, a expressão de LFY incrementaria, atingindo níveis satisfatórios à determinação floral. Já em plantas cultivadas sob fotoperíodos inibitórios, mínimo de 16 horas, até mesmo a expressão basal é fortemente reduzida, onde então os transcritos do ortólogo putativo de LFY hibridizados com a sonda antisenso não foram possíveis de visualização pela técnica utilizada. Em cortes longitudinais hibridizados com a sonda senso de LEAFY (controle negativo) nenhum sinal foi percebido, a não ser a coloração de fundo (figura 13; material amostrado na primeira coleta sob fotoperíodo natural).

Em adição, as análises anatômicas dos materiais corados via hibridização in situ e por safranina $1 \%$ propiciaram a descrição de caracteres diferenciais entre meristemas vegetativos e florais. Todos os detalhes anatômicos observados nos materiais corados por

Figures 5-13. In situ detection (dark red precipitate) of the transcripts from the putative Hyptis suaveolens homolog LEAFY gene at apical meristems. 5, 6. Transcripts have been uniformly detected at the vegetative and early axillary floral meristems from 30 day-old plants cultivated under natural photoperiod, as well as in leaf primordia. 7. Detection at the upper layers of floral meristem, in the tunica region (T), and in the sepal primordial from 60 day-old plant cultivated under natural photoperiod, whereas the signal intensity has decreased at deep zones, where there is predominance of vacuolated cells that compose the fundamental meristem (MF). 8. Detection in the petals and strong hybridization signal at the meristem apex and stamen primordial from 60 day-old plants cultivated under natural photoperiod. 9. Detection closed to the region of gynoecium differentiation, in a 150 day-old plant cultivated under natural photoperiod. 10. Signal at the anthers during the pollen producing in the microsporangia, in a 150 day-old plant cultivated under natural photoperiod. 11. Detection at the leaf primordia and vegetative meristem from 130 day-old plant cultivated under natural photoperiod. 12. Signal was not detected in the vegetative apex and leaf primordia from 150 day-old plant cultivated under at least 16 hours of photoperiod. 13. Absence of signal in the meristems hybridized with a LEAFY sense probe (30 day-old plant cultivated under natural photoperiod). Arrows $=$ the main tissue sites that the hybridizations have occurred. Bar $=25 \mu \mathrm{m}$ (figures 5, 7); $40 \mu \mathrm{m}$ (figure 6); $100 \mu \mathrm{m}$ (figures 8-10,13); $50 \mu \mathrm{m}$ (figures 11, 12). 
safranina são vistos em seções histológicas de materiais submetidos aos ensaios de hibridização in situ, e, assim, as imagens dos materiais hibridizados com a sonda heteróloga do gene $L F Y$ também são adequadas para a apresentação dos caracteres histológicos dos meristemas de $H$. suaveolens. Os meristemas florais analisados não apresentaram a organização típica de um ápice vegetativo e não foi possível acompanhar alterações citológicas características da transição de um meristema vegetativo para floral. A organização do meristema floral de $H$.
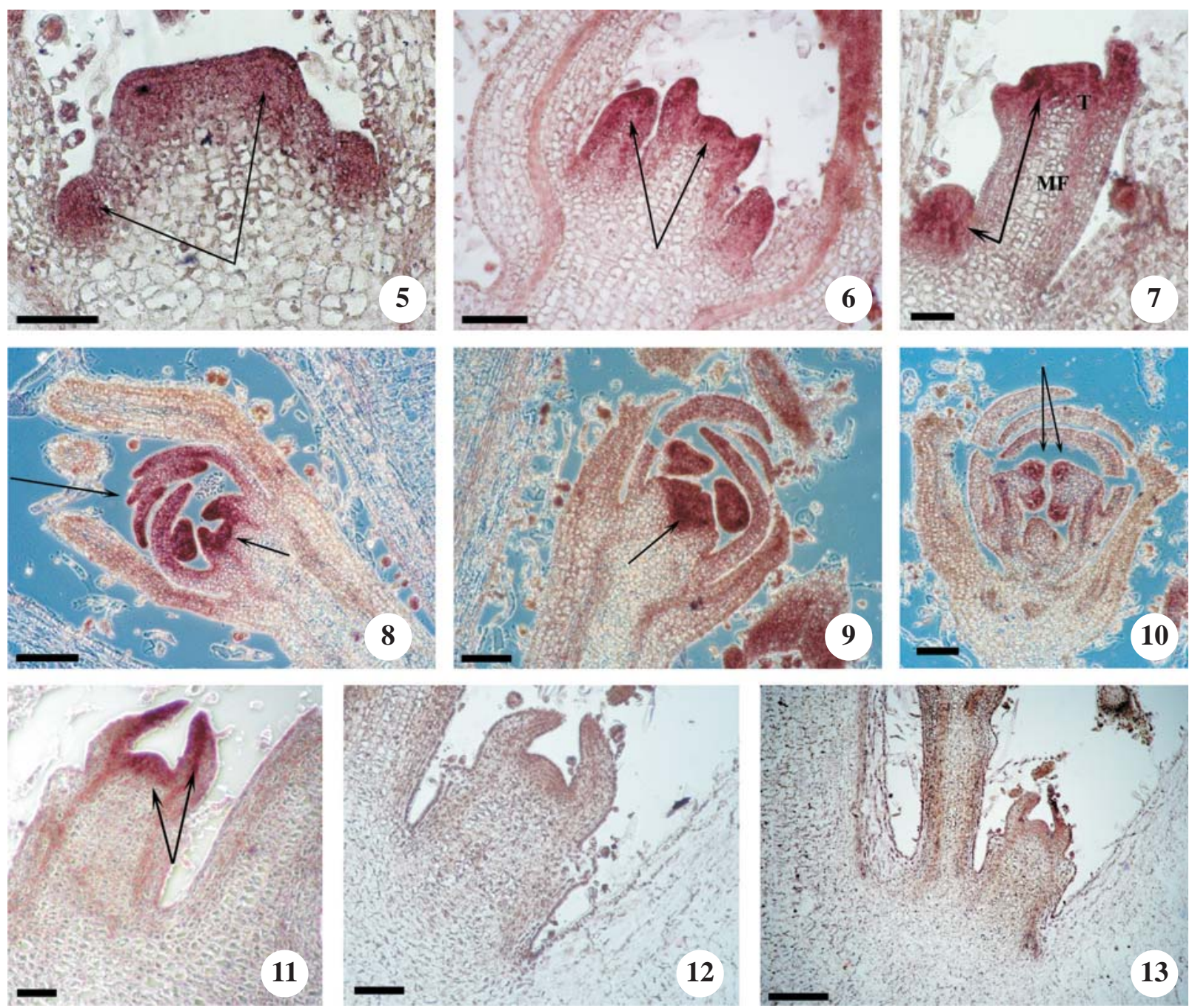

Figuras 5-13. Detecção in situ (precipitado vermelho escuro) dos transcritos do putativo ortólogo de LEAFY em meristemas apicais de Hyptis suaveolens. 5, 6. Detecção uniforme nos meristemas florais axilares em início de formação, em meristemas vegetativos e nos primórdios foliares de plantas de 30 dias de idade cultivadas sob fotoperíodo natural. 7. Detecção no ápice do meristema floral, na região da túnica $(\mathrm{T})$, e nos primórdios de sépalas de planta de 60 dias de idade cultivada sob fotoperíodo natural, porém ocorreu diminuição do sinal em porções basais do meristema, onde predominam células vacuolizadas formadoras do meristema fundamental (MF). 8. Detecção nas pétalas e forte sinal de hibridização no ápice meristemático e nos primórdios de estames de planta de 60 dias de idade cultivada sob fotoperíodo natural. 9. Detecção restrita à região de diferenciação do gineceu, em planta de 150 dias de idade cultivada sob fotoperíodo natural. 10. Sinal nas anteras, durante a formação do pólen nos microsporângios, em planta de 150 dias de idade cultivada sob fotoperíodo natural. 11. Detecção nos primórdios foliares e no meristema vegetativo de planta de 130 dias de idade cultivada sob fotoperíodo natural. 12. Sinal não foi detectado no meristema vegetativo e nos primórdios foliares de planta de 150 dias de idade cultivada em fotoperíodo mínimo de 16 horas. 13. Ausência de sinal nos meristemas hibridizados com a sonda senso de LEAFY (planta de 30 dias de idade cultivada sob fotoperíodo natural). Setas = principais sítios tissulares onde ocorreram hibridizações. Barra $=25 \mu \mathrm{m}$ (figuras 5, 7); $40 \mu \mathrm{m}$ (figura 6); $100 \mu \mathrm{m}$ (figuras 8-10, 13); $50 \mu \mathrm{m}$ (figuras 11, 12). 
suaveolens se revelou similar às descrições de meristemas florais de outras espécies vegetais (Oliveira et al. 2001, Reinheimer et al. 2005, Hochwallner \& Weber 2006, Carmona et al. 2007), apresentando células do ponto central do ápice em atividade meristemática reduzida, quando comparadas às células da extremidade apical, vacuolizadas, pouco coradas, formando o meristema fundamental que é encerrado pela túnica (figura 7).

A discriminação entre meristemas vegetativos e florais foi possível através de características anatômicas pronunciadas antes e após a organogênese foliar e das sépalas. Anteriormente à emissão dos primórdios foliares, os meristemas vegetativos apresentaram regiões anatômicas típicas (Kwiatkowska 2004) (figura 5), e a emissão dos primórdios foliares foi precedida por um desenvolvimento longitudinal relativamente pequeno do meristema (figuras 6, 11, 12). Por outro lado, os meristemas florais não apresentaram as mesmas regiões anatômicas de um ápice vegetativo e a emissão das sépalas ocorreu após o meristema ter sofrido maior extensão longitudinal em comparação ao ápice vegetativo (figura 7). Diferenças semelhantes na morfometria entre ápices vegetativos e florais são relatadas em outras espécies, como em Arabidopsis thaliana (Dewitte et al. 2007). Outra diferença reside no achatamento do meristema floral imediatamente após a emissão das sépalas (figura 7), enquanto que o ápice vegetativo adquiriu um formato cônico após a emissão dos primórdios foliares (figuras 11, 13). Este achatamento meristemático após a iniciação dos primórdios de sépalas é típico deste estágio de diferenciação floral (Pereira et al. 2003).

Hyptis suaveolens é uma planta de dias curtos, com fotoperíodo crítico oscilando próximo a $13 \mathrm{~h}$. Esta espécie não sofre transição para floração e o meristema floral não apresenta a organização típica de um ápice vegetativo. A atividade meristemática, de um meristema aéreo vegetativo ou floral, pode ser claramente evidenciada através da densidade celular. Os resultados relativos ao padrão de expressão de um ortólogo putativo de LFY em H. suaveolens indicam a possibilidade de conservação dos elementos moleculares iniciadores do processo reprodutivo nesta espécie. Contudo, são necessários estudos adicionais envolvendo isolamento, clonagem e análise da sequiência nucleotídica de um provável HsLFY, bem como hibridizações de Southern e Northern e ensaios de complementações gênicas em plantas modelos mutantes. Todavia, esforços maiores devem ser realizados com intuito de esclarecer a função de LEAFY em meristemas vegetativos e florais e assim estabelecer correlações entre o padrão de expressão deste gene descrito em $H$. suaveolens e mecanismos adaptativos em espécies invasoras.
Agradecimentos - Ao Conselho Nacional de Desenvolvimento Científico e Tecnológico (CNPq) pela bolsa de Iniciação Científica (F. T. Martins) e à Fundação de Amparo à Pesquisa do Estado de Minas Gerais (Fapemig) pelo auxílio à pesquisa. Aos professores F. C. A. Tavares e G. Bandel (Departamento de genética da ESALQ/USP) pelo suprimento das condições laboratoriais necessárias ao desenvolvimento do estudo, e ao professor E. W. Kitajima (NAP/MEPA, ESALQ/USP) por cordialmente ceder o microscópio eletrônico de varredura para realização das análises morfológicas. Agradecimentos especiais a Marcelo C. Dornelas pela imprescindível colaboração nas análises moleculares por hibridização in situ, e também nas análises por microscopia eletrônica de varredura.

\section{Referências bibliográficas}

AKAH, P.A. \& NWAMBIE, A.I. 1993. Nigerian plants with anti-convulsant property. Fitoterapia 64:42-44.

ALVES, A.C., MUNDSTOCK, C.M. \& MEDEIROS, J.D. 2000. Sistema vascular e controle do desenvolvimento de perfilhos em cereais de estação fria. Revista Brasileira de Botânica 23:59-67.

ASEKUN, O.T., EKUNDAYO, O. \& ADENIYI, B.A. 1999. Antimicrobial activity of the essential oil of Hyptis suaveolens leaves. Fitoterapia 70:440-442.

BABU, S.P.S. \& SUKUL, N.C. 1990. Essential oils as nematicidal principles. Environment and Ecology 8:1118-1120.

BERLYN, G.P. \& MIKSCHE, J.P. 1976. Botanical microtechnique and cytochemistry, Iowa State University Press, Ames.

BLÁZQUEZ, M.A., SOOWAL, L.N., LEE, I. \& WEIGEL, D. 1997. LEAFY expression and flower initiation in Arabidopsis. Development 124:3835-3844.

BOEHRINGER MANNHEIM/ROCHE. 2000. Nonradioactive in situ hybridization application manual. http:// www.roche-applied-science.com/prod_inf/manuals/ InSitu/InSi_toc.htm (acesso em 20/01/2005).

BOMBLIES, K., WANG, R.L., AMBROSE, B.A., SCHMIDT, R.J., MEELEY, R.B. \& DOEBLEY, J. 2003. Duplicate FLORICAULA/LEAFY homologs zfl1 and zfl2 control inflorescence architecture and flower patterning in maize. Development 130:2385-2395.

CARMONA, M.J., CUBAS, P., CALONJE, M. \& MARTÍNEZZAPATER, J.M. 2007. Flowering transition in grapevine (Vitis vinifera L.). Canadian Journal of Botany 85: 701-711.

CARVALHO, D.A. \& MARTINS, F.R. 1994. Sobre a similaridade de cerrados do sudoeste de Minas Gerais. Cerne 1:135-145.

COEN, E.S., ROMERO, J.M., ELLIOT, R., MURPHY, G. \& CARPENTER, R. 1990. FLORICAULA: a homeotic gene required for flower development in Antirrhinum majus. Cell 63:1311-1322. 
CORBESIER, L., GADISSEUR, I., SILVESTRE, G., JACQMARD, A., \& BERNIER, G. 1996. Design in Arabidopsis thaliana of a synchronous system of floral induction by one long day. Plant Journal 9:947-952.

DEWITTE, W., SCOFIELD, S., AlCASABAS, A.A., MAUGHAN, S.C., MENGES, M., BRAUN, N., COLLINS, C., NIEUWLAND, J., PRINSEN, E., SUNDARESAN, V. \& MURRAY, J.A.H. 2007. Arabidopsis $\mathrm{CYCD}_{3}$ D-type cyclins link cell proliferation and endocycles and are rate-limiting for cytokinin responses. Proceedings of the National Academy of Sciences of United States of America 104:14537-14542.

DORNELAS, M.C., WITTICH, P.E., VON RECKLINGHAUSEN, I.R., VAN LAMMEREN, A.A. M. \& KREIS, M. 1999. Characterization of three novel members of the Arabidopsis SHAGGY-related protein kinases (ASK) multigene family. Plant Molecular Biology 39:137-147.

DORNELAS, M.C., VAN LAMMEREN, A.A. \& KREIS, M. 2000. Arabidopsis thaliana SHAGGY-related protein kinases (AtSK11 and 12) function in perianth and gynoecium development. Plant Journal 21:419-429.

DORNELAS, M.C., AMARAL, W.A.N. \& RODRIGUEZ, A.P.M. 2004. EgLFY, the Eucalyptus grandis homolog of the Arabidopsis gene $L F Y$ is expressed in reproductive and vegetative tissues. Brazilian Journal of Plant Physiology 16:105-114.

DORNELAS, M.C. \& RODRIGUES, A.P.M. 2005. The rubber tree (Hevea brasiliensis Muell. Arg.) homologue of the LEAFY/FLORICAULA gene is preferentially expressed in both male and female floral meristems. Journal of Experimental Botany 56:1965-1974.

FALCÃO, D.Q. \& MENEZES, F.S. 2003. Revisão etnofarmacológica, farmacológica e química do gênero Hyptis. Revista Brasileira de Farmacognosia 84:69-74.

FROHLICH, M.W. \& MEYEROWITZ, E.M. 1997. The search for homeotic gene homologs in basal angiosperms and Gnetales: a potential new source of data on the evolutionary origin of flowers. International Journal of Plant Sciences158:S131-S142.

FROHLICH, M.W. \& PARKER, D.S. 2000. The mostly male theory of flower evolution origins: from genes to fossils. Systematic Botany 25:155-170.

GOCAL, G.F.W., KING, R.W., BLUNDELL, C.A., SCHWARTZ, O.M., ANDERSEN, C.H. \& WEIGEL, D. 2001. Evolution of floral meristem identity genes. Analysis of Lolium temulentum genes related to APETALA1 and LEAFY of Arabidopsis. Plant Physiology 125:1788-1801.

GRASSI, P., NUNEZ, M. J., VARMUZA, K. \& FRANZ, C. 2005. Chemical polymorphism of essential oils of Hyptis suaveolens from El Salvador. Flavour and Fragrance Journal 20:131-135.

HOCHWALLNER, H. \& WEBER, A. 2006. Flower development and anatomy of Clusia valerioi, a Central American species of Clusiaceae offering floral resin. Flora 201:407-418.
HOFER, J., TURNER, L., HELLENS, R., AMBROSE, M., MATTHEWS, P., MICHAELS, A. \& ELLIS, N. 1997. UNIFOLIATA regulates leaf and flower morphogenesis in pea. Current Biology 7:581-587.

JOHANSEN, D.A. 1940. Plant microtechnique. MacGraw Hill, New York.

KELLY, A.J., BONNLANDER, M.B. \& WAGNER, R.D.M. 1995. NFL, the tobacco homolog of FLORICAULA and LEAFY, is transcriptionally expressed in both vegetative and floral meristems. Plant Cell 7:225-234.

KINGSTON, D.G., RAO, M.M. \& ZUCKER, W.V. 1979. Plant anticancer agents. IX. Constituents of Hyptis tomentosa. Journal of Natural Products 42:496-499.

KWIATKOWSKA, D. 2004. Structural integration at the shoot apical meristem: models, measurements, and experiments. American Journal of Botany 91:1277-1293.

KYOZUKA, J., KONISHI, S., NEMOTO, K., IZAWA, T. \& SHIMAMOTO, K. 1998. Down-regulation of RFL, the FLO/LFY homolog of rice, accompanied with panicle branch initiation. Proceedings of the National Academy of Sciences of the United States of America 95:1979-1982.

MALELE, R.S., MUTAYABARWA, C.K., MWANGI, J.W., THOITHI, G.N., LOPEZ, A.G., LUCINI, E.I. \& ZYGADLO, J.A. 2003. Essential oil of Hyptis suaveolens (L.) Poit. from Tanzania: Composition and antifungal activity. Journal of Essential Oil Research 15:438-440.

MARTINS, F.T., POLO, M., DOS SANTOS, M.H. \& BARBOSA, L.C.A. 2006. Variação química do óleo essencial de Hyptis suaveolens (L.) Poit., sob condições de cultivo. Química Nova 29:1203-1209.

MELO, R.M., GOUVÊA, C.M.C.P. \& SILVA, A.L. 2005. Prevention of median incisional hernia in the rat by ultrasonic therapy. Acta Cirúrgica Brasileira 20:100-108.

MENGHINI, A., MANTILACCI, G., POCCESCHI, N. \& TATANI, N.C. 1996. Composition and in vitro antifungal activity of the essential oil of Hyptis suaveolens Poit. from Cameroun. Rivista Italiana Eppos 7:435-440.

MULLER-SCHARER, H., SCHAFFNER, U. \& STEINGER, T. 2004. Evolution in invasive plants: implications for biological control. Trends in Ecology and Evolution 19:417-422.

NOEGROHO, S.P. \& SRIMULYANI, M.B. 1997. Larvicidal activity of Hyptis suaveolens essential oil toward $4^{\text {th }}$ instar Aedes aegypti larvae and gas chromatographicmass spectroscopic analysis of the oil. Majalah Farmasi Indonesia 8:160-170.

OLIVEIRA, J.M.S., MARIATH, J.E.A. \& BUENO, D.M. 2001. Desenvolvimento floral e estaminal no clone CP76 de Anacardium occidentale L.: cajueiro-anão precoce (Anacardiaceae). Revista Brasileira de Botânica 24:377-388.

OLIVEIRA, M.J., CAMPOS, I.F.P., OLIVEIRA, C.B.A., SANTOS, M.R., SOUZA, P.S., SANTOS, S.C., SERAPHIN, J.C. \& FERRI, P.H. 2005. Influence of growth phase on the essential oil composition of Hyptis suaveolens. Biochemical Systematics and Ecology 33:275-285. 
PEREIRA, I.A.M., PINTO, J.E.B.P. \& DAVIDE, L.C. 2003. Época da indução e evocação floral em Citrus sinensis (L.) Osbeck cv. Pêra Rio. Ciência Rural 33:857-862.

POLO, M. \& FELIPPE, G.M. 1983. Germinação de ervas invasoras: efeito de luz e escarificação. Revista Brasileira de Botânica 6:55-60.

QURESHI, S., RAI, M.K. \& AGRAWAL, S.C. 1997. In vitro evaluation of inhibitory nature of extracts of 18-plant species Chhindwara against 3-keratinophilic fungi. Hindustan Antibiotics Bulletin 39:56-60.

REINHEIMER, R., POZNER, R. \& VEGETTI, A.C. 2005. Inflorescence, spikelet, and floral development in Panicum maximum and Urochloa plantaginea (Poaceae). American Journal of Botany 92:565-575.

ROJAS, A., HERNANDEZ, L., PEREDA-MIRANDA, R. \& MATA, R. 1992. Screening for antimicrobial activity of crude drug extracts and pure natural products from Mexican medicinal plants. Journal of Ethnopharmacology 35:275-283.

ROSALES, N.M., JAMILENA, M., ZURITA, S., GOMEZ, P., CAPEL, J. \& LOZANO, R. 1999. FALSIFLORA, the tomato orthologue of FLORICAULA and LEAFY, controls flowering time and floral meristem identity. Plant Journal 20:685-693.

SHITSUKAWA, N., TAKAGISHI, A., IKARI, C., TAKUMI, S. \& MURAI, K. 2006. WFL, a wheat FLORICAULA/ LEAFY ortholog, is associated with spikelet formation as lateral branch of the inflorescence meristem. Genes and Genetic Systems 81:13-20.
SILVA, A.F., BARBOSA, L.C.A., SILVA, E.A.M., CASALI, V. W.D. \& NASCIMENTO, E.A. 2003. Composição química do óleo essencial de Hyptis suaveolens (L.) Poit. (Lamiaceae). Revista Brasileira de Plantas Medicinais 6:1-7.

SOUER, E., KROL, A.V.D., KLOOS, D., SPELT, C., BLIEK, M., MOL, J. \& KOES, R. 1998. Genetic control of branching pattern and floral identity during Petunia inflorescence development. Development 125:733-742.

SOUTHERTON, S.G., STRAUSS, S.H., OLIVE, M.R., HARCOURT, R.L., DECROOCQ, V., ZHU, X., LLEWELLYN, D.J., PEACOCK, W.J. \& DENNIS, E.S. 1998. Eucalyptus has a functional equivalent of the Arabidopsis floral meristem identity gene LEAFY. Plant Molecular Biology 37:897-910.

TUKEY, J.W. 1991. The philosophy of multiple comparisons. Statistical Science 6:100-116.

VEIT, J., WAGNER, E. \& ALBRECHTOVÁ, J.T.P. 2004. Isolation of a FLORICAULA/LEAFY putative orthologue from Chenopodium rubrum and its expression during photoperiodic flower induction. Plant Physiology and Biochemistry 42:573-578.

WEIGEL, D., ALVAREZ, J., SMYTH, D.R., YANOFSKY, M. F. \& MEYEROWITZ, E.M. 1992. LEAFY controls floral meristem identity in Arabidopsis. Cell 69:843-859.

WULFF, R. 1973. Intrapopulational variation in the germination of seeds in Hyptis suaveolens. Ecology 54:646-649.

ZAIDAN, L.B.P., DIETRICH, S.M.C. \& SCHWABE, W.W. 1991. Effects of temperature and photoperiod on flowering in Hyptis brevipes. Physiologia Plantarum 81:221-226. 